\title{
FAMILY CENTERED MATERNITY CARE (FCMC) SEBAGAI SALAH SATU UPAYA MEMOTIVASI IBU HAMIL DALAM MENJAGA KESEHATAN SAAT KEHAMILAN BERBASIS KELUARGA
}

\section{Family Centered Maternity Care (Fcmc) As An Effort To Motivate Pregnant Mothers In Keeping Health During Pregnancy Family Based}

\author{
Siska Nurul Abidah ${ }^{1}$, Fritria Dwi Anggraini ${ }^{1}$ \\ ${ }^{1}$ Prodi S1 kebidanan, Fakultas Keperawatan dan Kebidanan, Universitas Nahdlatul Ulama \\ Surabaya \\ Email:Siskanurul@unusa.ac.id
}

\begin{abstract}
ABSTRAK
Motivasi yang diberikan keluarga kepada ibu hamil dalam menjaga kesehatan merupakan faktor utama untuk menjaga agar kehamilan berjalan sehat. Kegiatan pengabdian kepada masyarakat ini bertujuan untuk meningkatkan motivasi ibu hamil dalam menjaga kesehatan saat kehamilan dengan melibatkan keluarga. Pengabdian kepada masyarakat ini dilakukan di Desa Kedungpring selama 1 bulan dengan melibatkan sebanyak 35 ibu hamil dan keluarga. Metode yang dilakukan adalah dengan cara kunjungan rumah dengan pendekatan keluarga (FCMC) dengan protokol kesehatan ketat dengan cara memberikan educative menggunakan lembar balik dan power point pada leptop tentang pentingnya keterlibatan keluarga dalam memberikan dorongan motivasi kepada ibu hamil dengan menggunakan metode ceramah, tanya jawab dan praktik. Sebelum penyampaian materi para peserta diberikan pretest dan setelah penyampaian materi diberikan posttest untuk mengukur tingkat pemahaman peserta. Hasil dari kegiatan ini didapatkan ibu hamil mempunyai pengetahuan baik tentang menjaga kesehatan selama kehamilan berbasis keluarga diperoleh hasil pre test sebanyak 8 orang $(22,9 \%)$ sedangkan hasil post test peserta yang memiliki pengetahuan yang baik diperoleh hasil sebanyak 32 orang $(91,4 \%)$ sehingga ada peningkatan kemampuan dan pengetahuan keluarga akan pentingnya dorongan motivasi kepada ibu hamil sehingga keluarga mempunyai kesiapan dalam melakukan pemantuan kesehatan ibu hamil. Untuk pengabdian kepada masyarakat selanjutnya selain berbasis keluarga perlu dilakukan upaya-upaya lanjutan dengan melibatkan bidan desa dan kader.
\end{abstract}

Kata Kunci : Kehamilan, Dukungan Berbasis Keluarga

\begin{abstract}
The motivation given by the family to pregnant women in maintaining health is the main factor to keep the pregnancy going healthy. This community service activity aims to increase the motivation of pregnant women in maintaining health during pregnancy by involving the family. This community service was carried out in Kedungpring Village for 1 month involving as many as 35 pregnant women and their families. The method used is home visits with a family approach (FCMC) with strict health protocols by providing education using flipcharts and power points on laptops about the importance of family involvement in providing motivational encouragement to pregnant women by using lecture, question and answer methods, and practice. Before giving the material for the pretest participants and after giving the posttest material, it is given to measure the level of understanding of the participants. The results of the activities obtained by pregnant women who have good knowledge about maintaining health during family-based pregnancy obtained the pretest results of 8 people (22.9\%) while the post test results of participants who had good knowledge obtained the results of 32 people (91.4\%). there is an increase in the ability and knowledge of the family about the importance of motivational encouragement to pregnant women so that families have readiness in monitoring the health of pregnant women. For further community service, apart from family-based, further efforts need to be made to involve village midwives and cadres.
\end{abstract}

Keywords: Pregnancy, Family Based Support 


\section{PENDAHULUAN}

Motivasi dalam menjaga kesehatan merupakan faktor utama untuk menjaga agar kehamilan berjalan sehat serta dapat mendeteksi dini resiko tinggi sehingga tidak terlambat dalam melakukan penanganan.

Hal ini diperlukan kehadiran seseorang yang di anggap penting sehingga dapat memberikan motivasi kepada ibu hamil yaitu keluarga. Dari hasil wawancara peneliti yang dilakukan kepada 3 ibu hamil didapatkan hasil bahwa mereka mengatakan suami bekerja berangkat pagi dan pulang malem, sehingga tidak ada waktu mengantar periksa kehamilan, responden yang kedua mengatakan suami bekerja sebagai buruh, memiliki waktu yang banyak tetapi suami mempunyai anggapan bahwa kehamilan merupakan urusan wanita sendiri. Responden ketiga mengatakan suami menganggap ibu sudah tahu banyak tentang kehamilan karena sudah anak ketiga sehingga suami tidak terlalu terlibat dalam menjaga kesehatan ibu hamil.

Hal ini didukung oleh penelitian yang dilakukan arini dkk tahun 2015 mengatakan bahwa ada hubungan yang positif antara dukungan keluarga dengan ibu hamil, penelitian lain yang dilakukan oleh Laisaouw tahun 2020 juga mengatakan ibu hamil yang mendapatkan dukungan oleh suami kunjungan antenatal care nya lengkap. Dan ditambahkan lagi oleh penelitian yang dilakukan oleh Huriani dkk tahun 2020 mengatakan dukungan suami dapat mempengaruhi frekuensi antenatak care pada ibu hamil.

Pendekatan di dalam asuhan kebidanan komunitas dalam meningkatkan kesejahteraan ibu dan bayi yaitu pendeketan yang melibatkan keluarga yang dikenal dengan istilah family centered maternity care (FCMC) (Retna, 2017). Kegiatan Family Centered Maternity Care (FCMC) sebagai salah satu upaya yang dapat memotivasi ibu hamil dalam menjaga kesehatan karena mendapatkan dukungan dan keterlibatan yang penuh dari semua keluarga. Pendekatan ini melibatkan keluarga agar keluarga mau ikut berpartisipasi dalam memantau kehamilan, dengan cara mengenali dan menghargai keterlibatan keluarga, memberikan dorongan untuk mengenali dan membangun kekuatannya, mambantu membuat keputusan terbaik dengan menciptakan pola hidup yang sehat. Sehingga melalui pendekatan FCMC keluarga dapat memberikan motivasi kepada ibu hamil dalam menjaga kesehatan selama kehamilannya dan berdampak positif yaitu ibu hamil akan merasa nyaman, aman, tentram dan percaya diri.

\section{METODE}

\section{Waktu dan Tempat Pelaksanaan}

Program kegiatan pengabdian kepada masyarakat ini diadakan di Desa Kedungpring Balongpanggang Gresik. Kegiatan dilaksanakan selama 1 bulan pada bulan Mei sampai Juli 2021.

\section{Sasaran Peserta}

ibu hamil dan keluarga di Desa Kedungpring Balongpanggang sebanyak 35 responden .

\section{Tahapan Pelaksanaan}

1) Kegiatan dilaksanakan dengan melakukan kunjungan rumah dengan protokol kesehatan ketat dengan cara memberikan penyuluhan, melakukan diskusi tanya jawab dan praktik.

2) sasaran dalam kegiatan ini adalah ibu hamil dan keluarga

3) alat yang digunakan yaitu: lembar balik, modul kehamilan, leptop dan alat tulis

4) langkah-langkah kegiatan sebagai berikut:

a) melakukan pendataan ulang ibu hamil

b) melakukan kunjungan rumah dengan melakukan pendekatan keluarga ibu hamil, memberikan penjelasan tujuan dari kegiatan pengabdian masyarakat dan meminta kesediaan untuk ikut serta dalam kegiatan pengabdian masyarakat.

c) Hari kedua, melakukan kunjungan rumah lagi sesuai dengan waktu yang sudah disepakati bersama. Melakukan pretest dengan cara memberikan penyuluhan sesuai dengan modul kehamilan.

d) Hari ketiga, melakukan simulasi bagaimana melakukan tanggap darurat jika ibu hamil mengalami hal yang tidak diingikan dengan cara menyiapkan dan apa yang harus disiapkan keluarga.

e) Hari keempat, melakukan evaluasi dan post test 


\section{Monitoring dan Evaluasi}

1) Evaluasi penyuluhan

Setiap penyampaian materi para peserta akan selalu diberikan pretest dan posttest untuk mengukur tingkat pemahaman peserta sehingga mengetahui sejauh mana keberhasilan materi yang disampaikan.

2) Evaluasi kegiatan

Setiap kegiatan terdapat penilaian terstandar untuk memotivasi peserta agar lebih peduli dengan kesehatan pribadi dan lingkungan

3) Evaluasi pembentukan unit

a) Terdapat program Family Centered Maternity Care (FCMC)

b) Terlaksananya kegiatan atau program yang ada di Desa Kedungpring

\section{HASIL DAN PEMBAHASAN}

Tabel 5.2 Pre test dan Post Test Pengetahuan Tentang Menjaga Kesehatan Selama Kehamilan Berbasis Keluarga

\begin{tabular}{cccccccc}
\hline \multicolumn{4}{c}{ Pre Test } & \multicolumn{4}{c}{ Post Test } \\
\hline \multicolumn{2}{c}{\begin{tabular}{c} 
Pengetahuan \\
\multicolumn{2}{c}{ Baik }
\end{tabular}} & $\begin{array}{c}\text { Pengetahuan } \\
\text { Kurang }\end{array}$ & \multicolumn{2}{c}{$\begin{array}{c}\text { Pengetahuan } \\
\text { Baik }\end{array}$} & $\begin{array}{c}\text { Pengetahuan } \\
\text { Kurang }\end{array}$ \\
\hline $\mathrm{N}$ & $\%$ & $\mathrm{~N}$ & $\%$ & $\mathrm{~N}$ & $\%$ & $\mathrm{~N}$ & $\%$ \\
\hline 8 & 22,9 & 27 & 77,1 & 32 & 91,4 & 3 & 8,57 \\
\hline
\end{tabular}

Berdasarkan tabel 5.2 hasil pre test menunjukkan bahwa peserta yang memiliki pengetahuan baik tentang menjaga kesehatan selama kehamilan berbasis keluarga diperoleh hasil pre test sebanyak 8 orang $(22,9 \%)$, sedangkan hasil post test peserta yang memiliki pengetahuan yang baik tentang menjaga kesehatan selama kehamilan berbasis keluarga diperoleh hasil sebanyak 32 orang $(91,4 \%)$. Dari hasil tersebut menunjukkan ada peningkatan pengetahuan peserta sebelum dan sesudah dilakukan penyuluhan, sehingga kegiatan Family Centered Maternity Care (FCMC) yang dilakukan di desa kedungpring berbasis keluarga untuk memotivasi ibu hamil agar lebih menjaga kehamilannya, ibu hamil merasa tenang, percaya diri dan nyaman berhasil di lakukan.

Kegiatan Family Centered Maternity Care (FCMC) dapat menambah pengetahuan ibu hamil dan keluarga tentang pentingnya menjaga kesehatan saat kehamilan, keluarga ikut berpartisipasi dan peduli sehingga akan lebih siap dan siaga serta meningkatkan kemampuan keluarga dalam melakukan pendampingan ibu hamil jika ada resiko. Harapan dari kegiatan ini dilakukan psikologi ibu hamil dapat dijaga karena merasa dapat dukungan dari keluarga, kunjungan antenatal care K4 lengkap, ibu hamil yang memiliki resiko dapat terdeteksi secara dini untuk segera dapat penanganan dan program pendampingan ibu hamil yang memiliki resiko maupun tidak beresiko berbasis keluarga dapat berjalan dengan baik.

Hal ini diperkuat oleh penelitian yang dilakukan arini dkk tahun 2015 mengatakan bahwa dukungan keluarga sangat memberikan dampak positif kepada ibu hamil sehingga memiliki perasaan yang tenang, nyaman dan percaya diri. Penelitian lain yang dilakukan oleh Latifah tahun 2017 mengatakan bahwa dukungan emosional dan instrumental yang diberikan keluarga dapat menurunkan kecemasan pada ibu hamil.

\section{KESIMPULAN}

Kegiatan Family Centered Maternity Care (FCMC) dapat menambah pengetahuan ibu hamil dan keluarga tentang pentingnya menjaga kesehatan saat kehamilan. Dengan pengetahuan keluarga yang meningkat, keluarga mempunyai kesiapan dalam melakukan pemantuan kesehatan ibu hamil.

Diharapkan keluarga selalu ikut serta dalam pendampingan pada saat istrinya hamil, sehingga harapannya bidan dapat melakukan deteksi dini agar mencegah keterlambatan penanganan serta dapat memperkuat program kunjungan antenatal care (ANC) lengkap.

\section{DAFTAR PUSTAKA}

Arini budi astute, singgih wibowo $\mathrm{S}$ dan Muhana Sofiati Utami. 2015. Hubungan antara dukungan keluarga dengan penyesuaian diri perempuan pada kehamilan pertama. Jurnal psikologi. Vol 27 no. 2

Dinas Kesehatan Kabupaten Gresik. 2019. Buku pedoman kesehatan kabupaten gresik. Gresik:Dinas Kesehatan

Huriani, astin dan una zaidah. 2020. Hubungan tingkat pendidikan ibu hamil dan dukungan suami dengan frekuesni 
antenatal care ibu hamil di wilayah kerja puskesmas sedau. Jurnal ilmiah sangkareang mataram. Vol.6 no.2

Laisaouw, Meilany. 2020. Hubungan pengetahuan dan dukungan keluarga dengan kunjungan pemeriksaan antenatal care di puskesmas hila. Global Health science. Vo. 5 no. 1
Latifah, lailatul. 2017. Hubungan dukungan keluarga dengan kecemasan ibu hamil primigravida trimester III di wilayah kerja puskesmas pandian, sumenep. Jurnal ilmu kebidanan. Vol.3 No.1

Retna, eny ambarwati. 2017. Asuhan kebidanan komunitas. Yogyakarta:Nuha medika 